\title{
LOS EXILIOS POLÍTICOS Y LA DIMENSIÓN COMPARADA: CONTRIBUCIONES A UN CAMPO EN CONSTRUCCIÓN
}

\section{Political exiles and the comparative dimension: \\ Contributions to an emerging field}

\author{
Enrique Coraza de los Santos ${ }^{1}$, Mónica Graciela Gatica²
}

Fecha de recepción: 6 de marzo de 2016

Fecha de aceptación: 27 de octubre de 2016

1- Nacionalidad: Uruguayo. Grado: Doctor en historia. Especialización: Estudios de migración y procesos transfronterizos. Adscripción: El Colegio de la Frontera Sur. Correo: ecoraza@ecosur.mx

2- Nacionalidad: Argentina. Grado: Doctor en Historia. Especialización: Estudios de migración. Adscripción: Universidad. Nacional de La Patagonia. Correo: monicagracielagatica@yahoo.com.ar 


\section{Resumen}

Los estudios sobre los exilios en América Latina han tenido un desarrollo importante en los últimos veinte años. Si bien el recorrido mayor es el de los exilios del Cono Sur (Argentina, Chile y Uruguay), en los últimos años, han comenzado a aparecer textos, investigaciones y espacios académicos con trabajos sobre Paraguay ${ }^{3}$ o Colombia 4 , en menor medida, Centroamérica. Consideramos, que hemos llegado a un punto en el que debemos trascender los estudios de casos nacionales y comenzar a reflexionar sobre otros aspectos, planteamientos teóricos y metodológicos que busquen aportar elementos y ayuden a los análisis que, sobre estas migraciones forzadas, se están realizando. El objetivo, es reflexionar sobre la pertinencia de los estudios comparados sobre exilios de o en América Latina en el siglo XX considerando los avances ya realizados y algunos elementos sobre por dónde podría discurrir esta propuesta de trabajo.

Palabras clave: Exilios, América Latina, estudios comparados, metodología.

3- En relación a la bibliografía e investigaciones publicadas en torno al exilio paraguayo no son demasiados, ni pretendemos registrar de modo exhaustivo su producción, pero existe un corpus de fuentes y análisis de caso. A saber: COFADEP. s/f. Semillas de Vida-Nemity Ra. Asunción: Comisión de Familiares de Detenidos Desaparecidos Paraguayos en la Argentina (COFADEP); Abente-Brun, Diego. 2010. "Despues de la dictadura”. En Ignacio Telesca (coord.) Historia del Paraguay. Asunción: Taurus; Arellano, Diana. 2009. "Del posconflicto a la tradición de la democracia en Paraguay: rituales de reconciliación” [en línea]. En: <http://www.ram2009/unsam.edu. ar> [Consulta: 28 octubre 2011]; Arellano, Diana. 2013. "Reparar lo irreparable: Las víctimas de exilio frente a las políticas de reparación social en Paraguay”. En Testimonios, 3; Bareiro, Line. 2006. Prólogo. En Alfredo Boccia Paz, Myriam Gónzalez y Rosa Palau, Es mi informe. Los archivos secretos de la policía de Stroessner. Asuncion: CDE-Servilibro; Sánchez, María Antonia y Roniger, Luis. 2010. "El destierro paraguayo. Aspectos transnacionales y generacionales". En Revista Mexicana de Ciencias Políticas y Sociales, 52: 135-58; Senkman, Leonardo. 2013. "The Latin American Diasporas: New Collective Identities and Citizenship Practices”. En Mario Sznajder, Luis Roniger and Carlos A. Forment, eds. Shifting Frontiers of Citzenship. Leiden: Brill, pp. 385-407.

4- A propósito del exilio colombiano, el producido por uno de los conflictos internos más longevos en toda América Latina se puede decir, que a pesar de la magnitud e importancia que reviste, no son mucho los trabajos que se han realizado sobre estos exilios. En los últimos años han aparecido algunos a la luz del inicio de los Diálogos de Paz que, además de poner sobre la mesa el tema del retorno como parte de la normalización política y social, ha generado que se comiencen a desarrollar reflexiones y análisis sobre este fenómeno. Entre los trabajos encontrados se pueden citar: Vélez Rodríguez, Jhon. 2013. "El exilio como agente potencial de cambio en el presente y el futuro de la sociedad. La experiencia del Movimiento Nacional de Víctimas de Crímenes de Estado en Colombia (MOVICE) en Madrid" [Thesis submitted for the degree of Master in Philosophy]. Manchester: Faculty of Humanities, University of Manchester; CNMH. 2015. Voces del Exilio, Memorias de Colombianos en el Exterior. Bogotá: Departamento para la Prosperidad social, Gobierno de Colombia; Restrepo Vélez, Ofelia. 2006. Mujeres colombianas en España: historias, inmigración y refugio. Bogotá: Editorial Pontificia Universidad Javeriana, Instituto de Estudios Sociales y Culturales Pensar Pontificia Universidad Javeriana; Martínez Leguízamo Jeisson Osvaldo. 2015. "Exiliados colombianos en España: participación política transnacional en el marco de oportunidades de los Diálogos de Paz". En F. J. García Castaño, A. Megías Megías, \& J. Ortega Torres (Eds.). Actas del VIII Congreso sobre Migraciones Internacionales en España. Granada: Universidad de Granada; Martínez Leguízamo. Jeisson Osvaldo. 2014. "Incorporación de exiliados colombianos en España: Nuevos marcos para la ciudadanía”. En Mourad Aboussi (Dir.), Actas del I Seminario de Investigación Social Aplicada. Granada: Universidad de Granada; Riaño, P. y Villa, M. 2008. Poniendo tierra de por medio: Migración forzada de colombianos en Colombia, Ecuador y Canadá. Medellín: Corporación Región. 


\section{Abstract}

The study of exiles in Latin America has developed significantly in the last twenty years. Whereas most of this work concerns exiles from the Southern Cone (Argentina, Chile and Uruguay), texts, research and academic spaces relating to Brazil, Paraguay, Peru, Colombia and, to a lesser extent Central America, have begun to make an appearance. We believe that the point has now been reached where national studies should be transcended, to begin a reflection on other aspects, including theoretical and methodological approaches, seeking to provide elements to assist in the analysis of these forced migrations. The objective is to reflect on the relevance of comparative studies to the issue of exile in or from Latin America in the twentieth century, consider the progress already made and the circumstances around forced migrations especially those daily movements of displaced people that challenge us.

Keywords: Exiles, Latin America, comparative studies, methodology. 


\section{Introducción}

Las relaciones frecuentes entre los hombres hacen fácil la comparación entre diversos relatos, excitan el sentido crítico; por el contrario, se cree fervientemente al narrador que, a largos intervalos y por difíciles caminos, trae rumores lejanos" (Bloch, 1982: 87)

$\mathrm{L}$ a preocupación por abordar desde diferentes ópticas el análisis de los exilios en el Cono Sur ha adquirido relevancia, profundidad y complejidad en este nuevo siglo, tal vez y quizás más allá del proceso de investigación en sí mismo, por el imperativo que nuevas realidades, como los desplazamientos forzados por violencia social o ciudadana o, el creciente número de personas que están solicitando refugio o asilo, suponen hoy.

Nos referimos a una migración particular por su carácter forzado: el exiliado hubiese deseado quedarse, pero fue expulsado, o debió dejarlo para preservarse de persecuciones o de amenazas graves, migró forzosamente para salvaguardar su propia vida, o la de sus seres más próximos, buscando garantizar la libertad.

[El destierro]...es la grieta insalvable producida por la fuerza entre un ser humano y su lugar de nacimiento, entre yo y su verdadero hogar. La desdicha esencial de esta ruptura no puede superarse. Ciertamente existen historias que presentan al exilio como una condición que abre la vida a episodios heroicos, románticos, gloriosos y hasta triunfales. Pero son sólo historias, esfuerzos para vencer la inválida desdicha del extrañamiento. Los logros de cualquier exiliado están permanentemente carcomidos por su sentido de pérdida (Chedid: 2003: 87)

Hay suficientes producciones como para trascender los estudios particulares y permitirnos abordar estudios comparados, tanto desde lo sincrónico como desde lo diacrónico. Ahora bien, la problemática que nos ocupa, entendemos se inscribe en un contexto de angustia y fragmentación: convivimos en América Latina, y en el mundo todo, con refugiados, -hombres, mujeres, niños, niñas y jóvenes desplazados- inmersos en procesos de migración masiva, ya sea desde la periferia hacia los países centrales; o bien hacia centros de atracción regional. Sus implicancias y efectos no sólo se aplican sobre las víctimas directas, sino que afectan a la totalidad de las sociedades; y cabe destacar abundando, que las dictaduras latinoamericanas han actuado como agentes fundacionales del neoliberalismo, siendo visibles después de más de cuarenta años muchos efectos colaterales y consecuentes con los niveles represivos impuestos. Así, hoy no podemos pensar la migración y la diáspora ignorando las características de la globalización.

Dutrénit (2008: 15) bien sostiene que "La expulsión que representa el exilio es una parte de la destrucción del tejido social. Es un componente de un pasado ausente que de manera tardía se fue haciendo presente en el espacio público," $\mathrm{y}$ a esa tarea buscamos aportar develando y problematizando.

El desafío, ahora se plantea en el orden metodológico: hay que explorar desde dónde se pueden realizar las comparaciones: si desde las experiencias exiliares, desde las realidades expulsoras o desde las

5- Cursiva de los autores. 
categorías y conceptos que busquemos relacionar. Indagar en la Historia Comparada, en la Sociología Histórica o en la Política Comparada pueden ser quizás herramientas adecuadas para el análisis.

Bien nos ha advertido Charles Tilly que las comparaciones suponen generalizaciones en tanto quienes las emplean procuran que todos los casos que componen una categoría se ajusten al mismo principio -en nuestro caso, adecuándose a la especificidad del exilio político- aunque adopten múltiples formas, alertando y dando cuenta de que se trata de clasificar estrategias y no tácticas de comparación. Este sociólogo, se ha referido a la comparación individualizadora, la que persigue contrastar casos específicos de un fenómeno para captar las peculiaridades de cada caso, y la comparación universalizadora que trata de explicar el hecho de que cada uno de los casos de un fenómeno sigue en esencia la misma regla. Ahora bien;

...en el extremo contrario a las comparaciones individualizadoras y universalizadoras, está la comparación que trata de identificar la diferencia, mientras que el cuarto y último empleo de la comparación no es ni individualizador, ni universalizador ni identificador de la diferencia, sino que es globalizadora (Tilly, 1991: 106)

Esta propuesta de Tilly consideramos que es adecuada y nos permite un interesante acercamiento a los exilios políticos del siglo XX. Esta visión de una comparación globalizadora la podemos observar si realizamos una mirada general, totalizadora, tanto en el sentido estadístico, por considerar que representan las experiencias de expulsión más masificadas de la historia de los diferentes países de América Latina como, por la complejidad de su estudio, al incluir a un número importante de actores a niveles locales, nacionales e internacionales a la vez que políticos, económicos, sociales, culturales, de organizaciones e instituciones. Desde ésta última perspectiva, nos parece muy oportuno pensar y problematizar las implicancias que suponen las formas de extrañamiento y despojo que estudiamos, en tanto hemos validado que fueron, y son, prácticas numerosas y extendidas, funcionando bajo la forma de destierros, exilios y extrañamientos pero que, definitivamente, suponen la instrumentación de mecanismos de exclusión institucionalizada.

Así, identificar las propiedades comunes y poder rastrear la pista de sus principios y orígenes, tal vez pueda aportarnos elementos para pensar y visibilizar el devenir de mujeres, hombres, niñas, niños y jóvenes despojados y violentados, estableciendo desde las ciencias sociales y las humanidades pero, especialmente, desde la historia, parámetros que nos permitan revisar casos negativos o de control.

Siguiendo a Sartori, entendemos pertinente prestar especial atención a la distinción de aquello que denominaríamos exilio como tal, dando cuenta de las características que deberían reunir las circunstancias vividas por cada persona, para ser incluidas dentro de ese concepto. Lo que su obra evidencia, es la importancia de los conceptos y, para esa precisión, de las características para identificar indicadores para llegar a construir conceptos, tanto en su dimensión abstracta como operacional. Resultaría pertinente intentar una definición del exilio que responda historizando sus peculiaridades. Por ejemplo, la masividad del exilio o su heterogeneidad, que parecieran características del siglo XX y XXI y, que ponen en tensión, la tradicional caracterización del exilio de políticos e intelectuales, complejizando entonces el universo de sujetos alcanzados o comprometidos.

Este trabajo es parte de las iniciativas de colaboración entre investigadores e investigadoras que, desde diferentes instituciones en América Latina y Europa venimos desarrollando análisis sobre los exilios po- 
líticos. Realizamos, en nuestras investigaciones, una aproximación crítica, en la que fuimos aprehendiendo y, tratando de actuar, con el suficiente cuidado para comprender los esquemas mentales y representaciones de exiliados y exiliadas. En este sentido buscamos estar atentos al impacto que las vivencias les produjeron y que, con nosotros, compartieron. En ellas apareció el dolor, la impotencia, pero se suscitó cierto empoderamiento al saberse y pensarse como sujetos menos anónimos. Sus historias, recogidas y escritas les otorgaron visibilidad no sólo en la comunidad, sino que vienen a completar y complejizar el relato más tradicional del exilio que no los había considerado, dando cuenta de la operación del presente sobre el pasado, e incluso generando cierta proyección sobre el porvenir (Gatica, 2011: 369).

Otro aporte que nos ha parecido significativo es el de Collier y Mahón (Ramos, 2012) quienes, partiendo de ciertas observaciones al abordaje de Sartori, establecen dos tipos de formación de conceptos: la de "familia de semejantes" y las "categorías radiales". En el primer caso, en tanto resultado de una revisión previa de los casos considerados donde está presente el fenómeno que deseamos estudiar para extraer los atributos (una familia de atributos) similares (semejantes) que nos permiten (a partir de la existencia de alguno de los mismos) definir el concepto. En el segundo, encuentran una subdivisión entre subcategorías centrales y no centrales. La central, es la que posee el significado general pero tomado en forma independiente, o en conjuntos de dos o más. Nuevamente, haciendo el ejercicio aplicado al concepto de exilio, en el primer caso, familia de semejantes, es donde debemos considerar las características que nos permiten movernos dentro de ciertos supuestos que llevan a definir a los actores como exiliados, exiliadas, o no. Si aplicamos el segundo criterio, el de las categorías radiales, en su sub categoría central es lo que podríamos ubicar en los casos que denominaríamos paradigmáticos (en la medida que poseen todas las características) y en la sub categoría no central en aquellos que muchas veces están en la frontera con otros tipos de migración como la expatriación, la migración por razones económicas, culturales o incluso en un punto un tanto controvertido y sujeto a debate como quienes acompañan al exiliado/a o los hijos e hijas. Proponemos, trabajar en un análisis teórico crítico que propicie una visión totalizadora o abarcativa a la que nos hemos referido, partiendo del análisis empírico de las experiencias revisadas, evitando construcciones rígidas, y propiciando reformulaciones plurales y que atiendan a sus contenidos, superando la rigurosa perspectiva historicista o linealmente causalista.

Otro aspecto a considerar en el cómo, es el papel que juega en la selección de casos la similitud y la diferencia. Por un lado, tenemos el denominado "método de similitud" establecido por Stuart Mill que enfatiza en que los casos elegidos deben coincidir en sus resultados aumentando la efectividad en casos muy distintos y el "método de la diferencia" donde se seleccionan casos positivos y negativos. El punto de partida de Mill es la lógica determinista donde todos los casos positivos deben presentar la causa y todos los negativos deben carecer de ella. Posteriormente Przeworski y Teune desarrollan el "diseño basado en los casos más diferentes" haciendo hincapié en la necesidad de elegir casos que más que fijarse en la similitud de los resultados había que elegirlos por la diferencia en las variables de control. A su vez, contraponen la versión de Mill del "método de la diferencia" la del "diseño de los casos más similares" donde establecer que cuanto mayor sea la similitud de los casos en algunos aspectos, mayor será nuestra capacidad para eliminar estas variables como explicaciones plausibles (Pérez, 2007: 6-14).

De la reflexión antes referida, se desprende que el objetivo fundamental es el control, es conocer para decir qué sí y qué no, para establecer una regla, un parámetro. Por tanto, deberíamos decir que nuestro interés es estudiar los diferentes exilios para establecer una serie de parámetros (contenidos en los casos 
considerados) y el empleo de categorías extraídas de un esquema conceptual que pueda ser generalizante. Ahora, ¿cuál sería el sentido de establecer estos esquemas generalizantes? Consideramos que el estudio comparado de diferentes exilios puede llegar a permitirnos diseñar una matriz dinámica (que se puede ir alimentando y modificando con nuevos estudios) que constituya un punto de partida a la hora de considerar variables, circunstancias, acercamientos teórico-metodológicos, miradas, enfoques. Esta pretensión, no supone ser algo rígido a modo de "modelo" sino que sirva de guía de inicio para plantear una ruta analítica para los exilios políticos. Como segunda contribución, los resultados nos ayudarían a generar ese caudal de conocimientos sobre esta temática que, al considerar elementos comunes de partida, permitirían mejorar y aportar a construir esta dimensión comparada. ${ }^{6}$ En este punto, podemos suscribir a lo expresado por Marc Bloch: "El método comparativo ofrece muchas posibilidades y considero que su generalización y perfeccionamiento constituye una de las necesidades más apremiantes que en la actualidad se imponen a los estudios históricos. Sin embargo, también hay que señalar que, como método, no es todopoderoso, pues en ciencia no existen los talismanes” (Bloch, 1999: 113).

Procuramos, desplegar claves para su comparación, atendiendo particularmente a las redes y estrategias, en tanto herramientas para visibilizar prácticas y comportamientos que suponen mallas generadoras de nuevas formas relacionales, y que abonan el resguardo de los capitales políticos e históricos que los regimenes que los han expulsado intentaron destruir. Son derroteros que necesariamente deben revisarse contemplando lo local, lo regional o nacional, y lo internacional, intersectado por la conceptualización de clase, generación y género. Tal vez, sea necesario no sólo avanzar en la conceptualización y establecimiento de un sujeto/objeto de estudio específico, sino en la formulación de una metodología determinada que aportará pero, también se enriquecerá en la dinámica propiciada por la comparación. El bagaje de experiencias exiliares latinoamericanas, africanas y asiáticas imponen una problematización superadora del más conocido exilio occidental que, ciertamente ha sido europeo o etnocentrista. ${ }^{7} \mathrm{Hemos}$ de referirnos a contextos específicos que imprimen formulaciones que deben ser atendidas aportando a la formulación de una construcción plural, dinámica, y dialéctica entre lo general y lo específico. No hemos de pensar el ejercicio sólo a partir de los distintos casos nacionales, sino de la urdimbre compleja que descubrimos al reducir la escala de análisis pero que debe ser revisada a partir de la totalidad - globalidad.

Tal vez, la particularidad del continente latinoamericano subyace en nuestra propuesta propiciando una relectura alternativa que de cuenta de realidades múltiples más difíciles de visualizar en los países centrales. El cuestionamiento a la naturalización del despojo y el extrañamiento será un emprendimiento complejo que se alimentará en la transdiciplinariedad para aprehender el exilio.

El desafío de trabajar, en el campo disciplinario de la Historia, ${ }^{8}$ con la perspectiva de la historia desde abajo para conocer las circunstancias exiliares, analizando las memorias y subjetividades que estas vivencias gestaron, y que, ahora han compartido y visibilizado, permite avanzar entonces reconstruyendo

6- Agradecemos en este punto los comentarios y aportes de la Dra. Soledad Lastra de la Universidad de La Plata.

7- Una revisión de la literatura sobre los exilios así catalogados nos permiten observar como estos análisis se realizan a partir de referencias europeas existiendo pocas o nulas referencias a los estudios sobre esta temática hechos en otras latitudes como América Latina, Asia o África.

8- También se podría hacer desde la antropología a través del método etnográfico, sin embargo, la visión de la historia desde abajo le agrega la dimensión política y una postura epistemológica comprometida con visibilizar ciertos sectores sociales generalmente excluidos de la Historia. 
multiplicidad de prácticas y experiencias; poniendo fin a muchos silencios impuestos por la represión que disciplinó a nuestras sociedades activando miedos y silencios; pero también, por cierto, dando cuenta de complicidades que por mucho tiempo han sido inasibles, o develando gestos y solidaridades.

Si (...) la migración y el exilio suponen 'una forma de ser discontinua', una disputa con el lugar de origen. (...)-y si- presupone una morada [home] inicial y la promesa final de una vuelta, las cuestiones que deben enfrentarse en route necesariamente abren una brecha en las fronteras de este itinerario. -Con lo que- la posibilidad de seguir identificándose con dichas premisas se debilita y se extingue. La memoria de esta pérdida radical, inscripta de manera persistente en la incierta suerte del viaje al extranjero, ha convertido al exilio en un símbolo sugestivo de nuestra época (Chambers, 1995: 15).

Las y los sujetos nos proporcionaron datos e información en torno a sus opiniones, deseos, expectativas y experiencias, que hubiese sido casi imposible registrar con otro tipo de investigación, pero la narración también supuso "reunir hilos diacrónicos de la propia identidad", al decir de Montesperelli (Gatica, 2011: 370).

Aun así, nos queda pendiente una pregunta ¿qué buscamos al comparar los exilios? Puede ser meramente establecer una precisión conceptual que nos permita comprender de qué se trata, cuáles son las características que lo definen como elementos causales pues, a partir de ellos, entonces, podremos comprender mejor las reacciones de los individuos, los grupos, las sociedades y las organizaciones e instituciones. Pero, también es una vía para relativizar los conocimientos que tenemos sobre esta realidad humana y política en esta tensión permanente entre lo analítico y lo subjetivo, o para sumar conocimientos, enfoques, miradas que permitirían desencadenar nuevas preguntas que, de otra forma, no se nos ocurrirían. ${ }^{9}$ La versión canónica o "desde arriba" muestra sus límites y será necesario revisitar los estudios de caso.

El exilio se acrecentó en el siglo XX, no sólo considerando el ámbito geográfico, sino también sus alcances sociales. Podemos sostener, que se masificó y se proletarizó, en el sentido de que involucró no sólo a una minoría política e intelectual perteneciente a las capas superiores o medias de la sociedad, sino que, también, y masivamente, ha comprometido a clases subalternas o populares, que se transformaron en vectores privilegiados de influencias políticas y culturales, tanto en dirección a las sociedades receptoras, como en los países de origen (Groppo, 2000:33). Ha involucrado a sectores muy numerosos a lo largo del último siglo, proyectándose también a este nuevo milenio, inscriptos en el fenómeno más vasto de los refugiados.

Compartimos, siguiendo al historiador italiano Maurizio Degl'Innocenti, -que- el exilio, definido como "alejamiento de la patria por razones políticas, raciales, religiosas, civiles, de manera impuesta legal $\mathrm{o}$ arbitrariamente por el poder dominante, o de manera voluntaria para escapar a persecuciones o a violencias físicas o psicológicas" (...) "constituye, por sus dimensiones y su importancia social, un elemento que caracteriza a la historia contemporánea” (Groppo, 2000:3).

El exiliado es, para Nicolás Casullo (Guelerman, 2011: 211), un sobreviviente olvidado, alguien que tira hacia atrás la historia, un desaparecido que regresa, aquellos que no fueron asesinados. No se supo de 
él y, luego, muy pocos lo escuchan. Entonces, gestar un espacio para que el testimonio de estos sujetos sea posible, requiere, no sólo comprender la voluntad de hablar, sino, principalmente, sus dificultades para preservar los sentimientos de identidad. En cada testimonio, se pone en juego "no solamente la memoria, sino también la reflexión sobre uno mismo" (Pollak, 2006: 55).

Es dable señalar, que prácticamente el exilio no está en las memorias públicas ni sociales y, aún sigue estando restringido a las memorias familiares o grupales en muchas de las realidades socio políticas y humanas que las han sufrido. Circunscribirlo entonces, a sus expresiones más organizadas, supone una adjetivación muy fuerte desde el presente, al no reconocer las experiencias y trayectorias de quienes vivieron el exilio en silencio. Es un gran desafío vencer su invisibilización y lograr que se empoderen a partir de nuestras intervenciones analíticas y empíricas. Al comparar derroteros, debemos atender que las migraciones forzadas, o los exilios fueron, y son, invisibilizados -desde las estructuras y los estados, pero también muchas veces por los propios sujetos involucrados-, en tanto se protegen o protegieron en esa opacidad; permaneciendo durante mucho tiempo en una especie de limbo, negándoseles y negándose ese status. Así, entonces, al iniciar desde el presente un proceso interpretativo, debemos considerar condiciones y circunstancias de evocación.

Fue muy estimulante la lectura del texto de Ricardo Forster El exilio de la palabra. En torno a lo judío, que nos permitió pensar - pensarnos, en tanto experiencia interrogativa, recuperando el peregrinar de múltiples hombres y mujeres, que recorrieron el territorio y nutren y, nutrieron, las distintas memorias que hoy pugnan por manifestarse. Esta experiencia, vinculada a la errancia y a la diáspora, subyace.

Roniger y Sznajder concluyen aludiendo a la problemática de la invisibilidad de exilios o refugios en el caso de países que vivían un contexto de expansión que, "los escapados se tornaron invisibles (y) su pasado siguió vivo -sólo- en la memoria, aunque colectivamente su impacto se sumó al de otros inmigrantes" (Yankelevich-Jensen, 2007: 58).

Así, tomando en cuenta entonces la narración de los testigos, procuramos atender a la aprehensión, a las reflexiones o interpretaciones de sus vivencias, comprendiendo en un sentido más profundo el modo en que actuaron, aportando a una historia total, que complementamos con la historia desde abajo, y con las voces de sus protagonistas. Las periodizaciones, tendrán que superar mandatos decimonónicos, implicando un avance complejo sobre la ilusión del respeto a los principios y valores democráticos de nuestras sociedades, propiciando un pasaje heterogéneo, plural y descentrado. Debemos atender a la ruptura de la linealidad cronológica, considerando la dialéctica entre pasado y presente.

Volviendo al sociólogo e historiador norteamericano a quién aludimos en extenso pero que resulta nodal a los fines de nuestra propuesta y, a sabiendas de la complejidad que hace que, muy pocas investigaciones alcancen estándares rigurosos, sus advertencias nos parecen muy pertinentes, en tanto las comparaciones que tratan de identificar la diferencia se vuelven peligrosas y poco válidas en la medida en que:

- Los argumentos que se examinan estén insuficientemente especificados o indicados.

- Las relaciones entre las unidades difieran de las especificadas por los argumentos examinados.

- Las comparaciones manejan numerosas unidades cuya comparabilidad con respecto a la pregunta planteada es precaria.

- Se manejen numerosas unidades cuya independencia con respecto a las características que se miden sea insegura. 
- Las relaciones entre ellas y su comparabilidad respecto a los argumentos examinados sea incierta.

- Las mediciones combinen diferentes niveles de agregación cuya pertinencia con respecto a las evidencias examinadas varíe.

-Las comprobaciones se apoyen en juicios de quienes no están familiarizado con las estructuras globales de las unidades.

-Los juicios agrupen observaciones concretas y complejas en categorías abstractas y simples (Tilly, 1991: 144-145).

Debe atenderse que la nacionalidad y la ciudadanía mutan en un ambiguo proceso de transformación personal y colectiva, que la historia y, las ciencias sociales y las humanidades deben develar en toda su complejidad (Roniger-Sznajder: 2005). Analizamos un flagelo, una pena severa, tal vez no la peor, pero si, y esto ya no admite ninguna discusión, un violentamiento no sólo individual sino colectivo al que debemos dotar de historicidad.

La especificidad entre exilio objetivo y subjetivo nos remite a la representación que, desde y, a partir de estas mujeres y hombres, se ha construido, lo que aplica y abona la interpretación, superando la agencia del sujeto individual para repensarlo y definirlo desde lo colectivo, avanzando en una indagación dialéctica que no descuide la estructura. Esta estructura, se concibe con una dimensión que nos permitiría trascender las comparaciones solamente en el plano sincrónico para alcanzar también el plano diacrónico donde aparecen fuertes puntos de contactos entre exilios y que hacen factible la aplicación de ciertos conceptos como los de redes. Como afirma Bloch, "La comparación crítica bien entendida no se satisface sólo con aproximar testimonios en un mismo plano temporal. Un fenómeno humano es siempre una malla de una serie que atraviesa las edades" (Bloch, 1999: 96).

Partiendo entonces, de una clave transnacional e histórica, y reflexionando a partir de estudios empíricos que están consolidándose y expandiéndose, surgen las necesidades de contar con un bagaje conceptual y teórico renovado, con diversas escalas, al que buscamos aportar.

Debe insistirse en que, estas investigaciones, pueden inscribirse en las esferas escondidas a que alude Thompson, abordando la migración a partir de historias de vida, conectando puntos de una narración explicativa, dando cuenta de los extremos del proceso (Thompson: 2005).

Sin querer llegar a una pretensión tan ambiciosa de generar leyes o generalizaciones absolutas, nos preguntamos si es posible desarrollar un conjunto de variables que nos permitirían aplicar estrategias de análisis comunes y, observar si se cumple una regla que podríamos expresar como: la situación de exilio deriva en una serie de actitudes y estrategias desarrolladas por los individuos y los grupos como vehículos en una lucha por acabar con las causas que lo generaron.

\section{Recorriendo lo comparativo}

Textualizar las migraciones forzadas, los exilios políticos en América Latina del siglo XX y XXI, ha representado un camino que se ha ido abonando y alimentando con altibajos a partir del inicio de este siglo. Los análisis sobre la producción historiográfica de estos destierros provocados por la violencia 
política, por los terrorismos de Estado y las Guerras Civiles en diferentes puntos de la geografía latinoamericana daban cuenta de sus lagunas al inicio de los 2000 para el Cono Sur (Jensen, 1998 y 2004; Coraza, 2001 y 2006), siendo un campo aún en construcción hoy en día para otros territorios como los centroamericanos (Coraza-Aldana, 2014). Este es el punto que marcaba Clara Lida a la hora de señalar las dificultades para comparar exilios de diferente origen que habían compartido un mismo espacio de destino como era su intención al hacerlo entre el exilio republicano español y el argentino en México señalando “...hay pocos estudios equivalentes sobre otros exilios que desde entonces llegaron a este país en busca de refugio" y sentenciaba una constatación sobre la historiografía de los exilios: “...éste rara vez se historia a sí mismo, aunque abunde en testimonios y memorias" (2002: 205).

No se ha avanzado demasiado en su consideración como fenómenos que, más allá de sus particularidades y diferencias en cuanto a momentos históricos y circunstancias contextuales, tiene elementos que se puedan trabajar como relacionados y no sólo en sus conexiones entre ellos, sino como fenómenos con cierto grado de similitud.

Transcurrida más de una década y, considerando que ya no forman parte de las memorias ausentes o silenciadas para ciertos países como Argentina, Chile o Uruguay y en menor medida para Brasil, Paraguay, Bolivia o Perú, se puede afirmar que existe un campo con entidad propia y con presencia dentro de los debates sobre el pasado reciente. En Centroamérica, entretanto, aún falta recorrer este camino de emergencia de las memorias, y hablar de migraciones forzadas es aludir muchas veces a actores ausentes. Ausentes del pasado que han sucumbido frente a otras figuras sociales triunfantes como la del combatiente guerrillero en El Salvador o la del desplazamiento forzado -los refugiados de las comunidades mayas en México para el caso de Guatemala y; ausentes del presente- al representar una realidad que discurre entre la incomodidad del reconocimiento y la urgencia del drama humanitario en la migración forzada por violencia en el países como Honduras, Guatemala o El Salvador hoy en día (Winton et al., 2014).

Sin embargo, y aun reconociendo las lagunas y los adeudos, sí se puede observar en estos exilios que comparten un doble carácter, el de ser resultado de diferentes formas de violencia política, y el de ser masivos, tienen elementos suficientes como para pensarse en otras claves, superando la más tradicional caracterización, trascendiendo los enfoques nacionales.

Son ya varias las voces de quienes reclaman desde distintos espacios académicos el reto de comenzar a pensar en formas de abordaje más amplias. Los corsés de las miradas nacionales comparten en la literatura exiliar los abordajes que daban cuenta de las experiencias de los colectivos de desterrados de un país en otro, trazando líneas que como mucho podían alcanzar un sentido de ida y vuelta en forma uni o bi direccional (Jensen, 2004 y 2010; Coraza, 2005 y Coraza-Dutrénit, 2010). Esto es un resultado muy claro en el caso del exilio republicano español, y especialmente en su destino mexicano con algunos avances en los últimos años en otros destinos como Argentina, Cuba, Chile, República Dominicana o Uruguay. Los primeros trabajos de análisis para el Cono Sur reprodujeron este esquema y se puede observar en las obras que con un carácter abarcativo querían dar cuenta de las experiencias de exiliados y exiliadas argentinos, chilenos o uruguayos por los distintos puntos del planeta, de América Latina y el Caribe a Europa occidental y oriental y hasta África (Coraza, 2006; Pozo, 2006; Yankelevich-Jensen, 2007 y Pla Brugat, 2007).

Lo que nos interesa, es revisar qué es lo que los autores y autoras consideran como elementos comparables para, posteriormente, establecer que el exilio es uno de esos conceptos factibles de ser compa- 
rados. Sartori nos aclara por dónde puede ir la deriva “...comparable (bastante similar) respecto a qué propiedades o características y, no comparable (demasiado distinto) respecto a qué otras propiedades o características" (Sartori, 2012: 35). Por tanto, consideramos que debemos ubicarnos en el plano macro de las movilidades de población y dentro de ellas considerar las experiencias micro de los exilios, pues son similares respecto al conjunto de características que los definen y los diferencian de otras formas de movimientos de población.

Como también prueba Franco, con estas migraciones políticas asistimos a experiencias y espacios activos, poblados por hombres y mujeres, en los que unos y otras construyeron nuevas prácticas y se redefinieron en ellas (Franco-Andújar et al., 2009: 128). Siendo entonces, el exilio un lugar de transformaciones múltiples, privadas pero también públicas, que ciertamente generaron escisiones entre ambas temporalidades. La consideración que recoge Montesperelli de Jedlowski en torno a la cuestión de cómo cada generación selecciona el pasado y lo interpreta y, al marco de plausibilidad que otorga la memoria colectiva a la memoria individual, parece demostrarse. De allí, la relevancia que tiene la dialéctica social en los recuerdos de estas experiencias traumáticas, expuestas y consideradas a partir del análisis de las distintas subjetividades revisadas; siempre atendiendo a que lo que se recuerda remite a conflictos entre distintas estrategias de legitimación, revisando los aparatos y modalidades de transmisión y, atendiendo, a la preponderancia de la memoria oficial frente a las subalternas. Este reto plantea muchas dificultades metodológicas pero, ha podido ser sorteado de modo bastante exitoso a partir del trabajo de análisis de las memorias, con la historia oral y, la relación de las clases populares con la escritura y narración de sus propias trayectorias. Es, particularmente relevante, la consideración de los límites que ejerce la experiencia, percibiéndose, muchas veces, como incomprensible para los propios involucrados, lo que ha derivado en enmudecimientos ante la falta de marcos sociales y lingüísticos que den cuenta de su exilio (Montesperelli en Gatica, 2011:335).

Volviendo al eje de la necesidad de la comparación para el caso de los exilios, nos parece importante recoger algunos reclamos que, desde hace unos años, se vienen dando en la historiografía sobre esta temática para señalar y fundamentar, aún más, nuestra propuesta.

El historiador español, también parte del exilio republicano, Claudio Sánchez Albornoz ya advertía en su texto "El exilio español en perspectiva comparada":

La historiografía contemporánea muestra (...) una clara y justificada preferencia por los estudios comparados. Confrontar situaciones afines para enriquecer el conocimiento de los casos y del conjunto. Sobre el exilio español escasean precisamente tales comparaciones. Correspondería pues abrirse a nuevos horizontes historiográficos y preguntarse para empezar ¿cuáles son las comparaciones posibles por dentro y por fuera? Los puntos de comparación básicos podrían ser fundamentalmente tres en relación con el exilio en México: el destierro español en México y en otros países americanos o europeos, el éxodo republicano y la emigración tradicional, y, en fin, el exilio español y los antifascistas. A estos puntos cabe agregar una pregunta frecuente ¿en qué se parece su diáspora a la de otros españoles anteriores a ellos? (Sánchez, 2002: 198). 
En la misma obra donde encontramos el texto de Sánchez Albornoz, Clara Lida, en su intento de comparación entre los exilios españoles y argentinos en México incursionaba en la perspectiva comparada:

Mi propósito será plantear ciertos contrastes entre ambos casos para entender cómo el estudio de uno puede iluminar la comprensión del otro (... ....este trabajo no pretende ser exhaustivo, sino comenzar a trazar algunos caminos para investigaciones futuras mediante hipótesis y sugerencias que, más que encontrar respuestas, pretenden iniciar las preguntas y la enumeración de los problemas (Lida, 2002: 205-206).

Sin embargo, la autora señalaba obstáculos fundamentales para poder establecer los elementos que llevaran a una adecuada comparación: “....será difícil avanzar en el camino si antes no conocemos mejor cada uno de los exilios a tratar. Los análisis comparativos exigen conocimientos equivalentes para cada caso..." (Lida, 2002: 208).

Finalizando la primera década del 2000 la necesidad de trascender en los análisis históricos los límites del estado nación tuvo su concreción en el Proyecto de Historia Comparada de las Américas:

...cuyo propósito de hacer Historia compartida por las naciones americanas, con sus encuentros, desencuentros, sus convergencias y divergencias. La metodología comparativa nos permite ubicar a cada proceso histórico en su contexto regional e internacional, y profundizar en su conocimiento (...) El objetivo del Proyecto Historia Comparada de las Américas es contribuir al conocimiento mutuo y con ello al entendimiento de los países que conforman la comunidad americana (Galeana, 2014: XI).

Esta iniciativa, desarrolla una serie de obras que, aplicando la perspectiva comparada, dotaban de contenido a este sentido a partir de ejes temáticos. Así, tenemos en el 2008 su obra de presentación con una perspectiva generalista, Historia comparada de las Américas y, a partir de 2010, con Historia comparada de las Américas: sus procesos independentistas, comienza esta mirada continuando en 2012 con Historia comparada de las mujeres en las Américas y, en 2014, abordan Historia comparada de las migraciones en las Américas, donde: “...se identifican el origen de los procesos migratorios, sus factores comunes y sus divergencias, así como las diferentes propuestas de solución” (Galeana, 2014: XIII).

Una obra importante, con un sentido amplio, tanto en lo temporal como en lo espacial, respecto a los exilios, es la de Sznajder y Roniger donde realizan un recorrido diacrónico y sincrónico de las migraciones forzadas y acciones de destierro en América Latina. Si bien no mencionan la perspectiva comparada como una estrategia metodológica sí, se puede observar, este esquema referido en cuanto a establecer ideas, ejes de análisis que se sustentan en un estudio pormenorizado de ejemplos en la historia de América Latina: “...analizaremos el uso recurrente y las transformaciones del exilio desde la época colonial hasta el presente en América Latina” (2010: 19). Sí existe una intencionalidad de trascender los esquemas tradicionales ya mencionados para otros productos de investigación pues afirman que “...el estudio sistemático del exilio también promete conducir a nuevas lecturas del desarrollo histórico latinoamericano, lejos de las lecturas tradicionales de las historias nacionales para moverse hacia dimensiones más regionales, trasnacionales, o aún continentales" (2010: 22). Su mirada, ya está estableciendo las bases 
sobre las que nos preguntamos sobre la posibilidad y pertinencia de un acercamiento a los exilios desde la perspectiva comparada:

Nuestra investigación comenzó con la búsqueda del común denominador más amplio del exilio político, así como de su rasgo más distintivo. Tal estrategia combinada conduce a desvelar aquello que los exiliados tienen en común con la arena más amplia de individuos y grupos desplazados que se trasladan y aquellos sesgos que los hacen singulares. En otras palabras, cuáles son los temas fundamentales que el exilio comparte con otras situaciones afines y cuáles son aquellos que convergen en el concepto de exilio político, distinto de la condición más amplia de desplazamiento (2010: 42).

Este desafío, de lo comparativo como una gran pregunta en pos de respuestas a la vez que metodológica, también de comprensión de fenómenos sociales, políticos y humanos en una dimensión más allá de las experiencias concretas, guarda un esquema que se ha repetido en otros ensayos similares. La recurrencia a reafirmar este llamado a la comparación como un reclamo de abordaje se apoya en la estrategia discursiva de elaborar preguntas disparadoras cuya respuesta darían sustento y legitimidad a dicho desafío.

En una ponencia presentada en la Feria Internacional del Libro de Guadalajara (México, 2010) Enrique Coraza, decía:

La propuesta es mirarlos desde epígrafes que intenten encontrar puntos de contactos y permitan reconstruir las relaciones que existen entre los diferentes exilios y casos nacionales, para, a partir de ellos, encontrar puntos en común que justifiquen nuestra propuesta de relato.

Las hipótesis de partida, los problemas que nos planteamos se pueden esbozar en una serie de preguntas, y sus respuestas en los análisis comparados intentarán desde la deconstrucción reconstruir la complejidad.

¿Dónde radica la particularidad de los exilios frente a otro tipo de migraciones? ¿En qué medida la relación entre sociedad, cultura y política, determina las formas de los exilios?

¿Cuál es el papel que desempeñan las redes previas establecidas en los niveles culturales, sociales, políticos y sindicales, en las formas que adoptan los exiliados y exiladas en su lugar de residencia?

¿Qué papel desempeña, como capital cultural, como sustrato de recursos, una red existente o una migración previa en las migraciones futuras? (Coraza, 2015: 21).

Con este esquema, se analizaron en forma comparativa los exilios español, argentino y uruguayo bajo una mirada relacional al analizar la presencia española en tres países, Uruguay, Argentina y México en correspondencia con los exilios argentinos y uruguayos en España y México. De esta forma se buscó realizar una triangulación comparativa entre el Cono Sur, España y México incidiendo en tres aspectos: los contextos de salida, los de llegada y las redes, estrategias y discursos. 
Por su parte, Silvina Jensen, también en un ejercicio de comparar dos experiencias exiliares como lo son la protagonizada por los republicanos españoles y los argentinos, buscó profundizar sobre esta posibilidad. Para ello problematiza sobre "...las posibilidades y peligros que comporta hacer una historia comparada..." concluyendo que “...se trata de una comparación factible (...) atendiendo, por un lado, a las cualidades inherentes a los casos de estudio y, por el otro, a la pertinencia de las preguntas que ordenan la comparación y que se sustentan en la perspectiva del historiador" Apoyándose en este esquema formuló preguntas que establece como rectoras de su propuesta comparativa: ¿quiénes se exiliaron?, ¿cuántos?, ¿cómo salieron?, ¿durante qué período? y ¿por qué? Su estudio se sustenta en tres bloques de análisis y un ejercicio de mayor abstracción: la problemática de la historia comparada aplicada a los exilios; la reconstrucción de ambas experiencias exiliares sobre la base de las preguntas ya señaladas y, finalmente, una discusión sobre las memorias de los exilios en ambas realidades nacionales, España y Argentina para encontrar sus singularidades y puntos de confluencia entre ambas (Jensen, 2014).

Explorando otras contribuciones que desde la Academia, aluden a lo comparativo en los exilios nos encontramos con el trabajo de Viviana Mellone (2014) quien se plantea la comparación de los exilios españoles e italianos en Londres en el primer cuarto del siglo XIX. Sin problematizar sobre la pertinencia y viabilidad de realizar los estudios comparados, basó su análisis en cómo se producen las relaciones de dos comunidades exiliares en su lugar de destino, en las interrelaciones con los ambientes políticos y literarios anglosajones, y cómo éstos actúan sobre las identidades de aquellas comunidades. Este trabajo se inscribe dentro de esta línea de comparaciones que parten de un problema de investigación, en este caso, las interrelaciones entre comunidades de exiliados y contexto político cultural de destino, como justificante de la comparación. De esta forma, lo que buscan este tipo de abordajes es sacar del particularismo los análisis relacionales y mostrar cómo tienen que ver más con la condición de colectividades exiliadas que con la particularidad de una nacionalidad en concreto. Como la autora lo explica:

La dimensión 'relacional' que la reciente historiografía ha atribuido al exilio, permite, en este punto, alimentar las relaciones entre Londres y cada una de las comunidades de refugiados. Se intentará demostrar que tales contactos incidieron profundamente en la identidad del grupo de italianos y españoles en vías de definición y que contribuyen a delinear -y en parte a disipar- los tratos específicos de aquella asociación mediterránea de la que podría haberse esperado una mayor consolidación al final del Trienio (2014: 443).

Existen algunos análisis de los exilios que a primera vista podrían ser considerados como comparativos, pero sin embargo, una lectura crítica de ellos muestra que no existe un planteamiento inicial o una intencionalidad de comparación sino, más bien, es la sumatoria de estudios en diferentes espacios o territorios. Este es el caso del trabajo de Andrea Pagni quien realiza un recorrido por el exilio republicano español por diferentes países de América Latina a partir de espacios culturales (Pagni, 2011). Lo mismo ocurre con algunos títulos de eventos académicos que pueden confundir sobre su real carácter en la práctica. Así lo podemos ver en la cita de académicos en Santiago de Compostela los días 14 y 15 de noviembre de 2014: "Los exilios ibéricos en clave comparada: Nos 70 anos da función do Consello de Galizia” organizado por el Consello de Galizia de Montevideo, el Arquivo da Emigración do Consello da 
Cultura Galega y la colaboración del Grupo de Investigación de Historia Politica e dos Nacionalismos de la Universidad de Santiago de Compostela. En él se dan cita académicos y académicas para analizar diferentes aspectos de los exilios. Sus objetivos de acuerdo al programa eran:

...propoñen, co concurso de acreditados especialistas de universidades galegas, europeas e latinoa-mericanas, unha reflexión transnacional e comparativa verbo das categorías conceptuais asociadas ao fenómeno dos exilios e das emigracións políticas en xeral, centrándose nas experiencias dos exilios antifascistas ibéricos e europeos no continente americano dende o período de entre-guerras, estudándoos igualmente tanto dende o punto de vista das sociedades receptoras como das emisoras, e procurando atender non só as dinámicas sociopolíticas e culturais específicas de cada caso, senón tamén a súa interacción e entrecruzamento. O obxectivo é procurarmos unha nova visión historiográfica dos exilios e do seu lugar dentro da historia do século XX, partindo dende o caso galego nunha perspectiva global. ${ }^{10}$

En las intervenciones, puede hacerse un recorrido por diferentes abordajes que más que una comparación, lo que realizan es una interrelación entre conceptos y circunstancias que sí podrían constituir elementos para análisis comparativos tanto para el caso de las diferentes regiones históricas españolas y sus exilios (gallegos, catalanes o vascos) como portugueses, especialmente los que se produjeron como resultado del avance del franquismo y el nazi fascismo en Europa. En este evento, y para el caso latinoamericano, Pablo Yankelevich aborda los exilios latinoamericanos en una perspectiva de larga duración -los siglos XIX y XX- y, sí desde una mirada relacional y comparativa, en la medida que, para los casos nacionales, éstos le permiten ser ejemplos para incidir en variables conceptuales, de causalidad, de composición, impacto, dimensiones, acciones, ámbitos, espacios, memorias o producción académica y literaria, así como detectar las ausencias existentes aún hoy de muchas aristas de las migraciones forzadas latinoamericanas.

Otro aspecto que ha sido sometido a comparaciones aunque, en menor medida, es el de los retornos. Considerando a éste como un elemento más de las migraciones y, en muchos casos, como el momento que podría considerarse más traumático (Coraza, 2014), en la medida que enfrenta lo imaginado, lo conservado como imagen fotográfica, en forma estática en el exilio, con lo real del país al que se retorna. Es, en este momento, donde aparecen todas las contradicciones y conflictos, desde los familiares a los políticos, culturales, afectivos, identitarios y memoriales. En esta mirada, es destacable el ejercicio de comparación realizado por Soledad Lastra sobre los retornos de los exilios uruguayos y argentinos (2014). Al inicio de su propuesta -ya expresada con mayor detalle en su tesis doctoral- ${ }^{11}$ nos muestra su intencionalidad:

10- Fuente: http://hispona.org/wp-content/uploads/exilios.pdf

11- Consultable en: https://www.academia.edu/7951967/Los_retornos_del_exilio_en_Argentina_y_Uruguay_Una_historia_comparada_de_las_pol\%C3\%ADticas_y_tensiones_en_la_recepci\%C3\%B3n_y_asistencia_en_las_posdictaduras_1983-1989_ 
A través de una perspectiva histórica comparada y de una amplia exploración de documentos escritos y orales este artículo postula que existieron claras diferencias en las intervenciones que los distintos actores del movimiento de derechos humanos, de los partidos políticos y también de los mismos sectores de exiliados, tuvieron en relación con la conformación de estos espacios y más generalmente a la instalación del tema del retorno en cada "agenda" pos dictadura. (...) ...con el propósito de realizar un análisis comparado sobre las respuestas que cada sociedad brindó a los retornados del exilio indagando desde una pregunta nodal sobre la conformación de estos espacios (2014: 71-73).

En un sentido similar, aunque en un nivel más inicial de la investigación, Coraza y Aldana también utilizan esta mirada para revisar los retornos en una clave comparada, observando los que se produjeron en Uruguay, con la experiencia de El Salvador, posterior a los acuerdos de paz a inicios de los años 90 del siglo XX:

...se intenta establecer algunos puntos de partida para comenzar a estudiar y analizar las migraciones forzadas de salvadoreños y salvadoreñas que tuvieron que huir de su país como consecuencia de la extensión de un sistema represivo extendido. Se reconoce las enormes distancias existentes entre las situaciones de partida entre las experiencias autoritarias y de dictaduras en el Cono Sur con las de Guerra Civil en Centroamérica. Sin embargo, podemos encontrar algunos aspectos en común en la medida que los exilios son el resultado de una situación de violencia individual, familiar y/o grupal y como consecuencia de la militancia política en organizaciones de carácter social, político o de la vía armada. De igual forma, a pesar de las diferencias, se pueden establecer puntos de comparación entre situaciones previas de militancia, ser sujetos de represión, circunstancias para la huida, rutas y modalidades (clandestinidad, uso de redes, refugio, asilo, paso irregular de fronteras, etc.) (Coraza-Aldana, 2014).

Así como señalamos la existencia de eventos académicos con esta perspectiva comparada para el caso de los exilios, encontramos una iniciativa similar para los retornos. Nos referimos al Seminario Permanente que organiza el Colegio de la Frontera Norte en forma anual, y que es retrasmitido a universidades y centros de investigación de América Latina, Europa y Estados Unidos. El ciclo del año 2014 estuvo dedicado al "Retorno y reemigraciones: una perspectiva comparada". ${ }^{12} \mathrm{Si}$ bien ninguna de las intervenciones realizó un análisis comparado, sí que la iniciativa marca esa necesidad de ver y atender esta dimensión para comprender las movilidades de población en general, no solamente para los exilios.

El enfoque histórico comparativo ha aportado mucho pues, agrega al análisis sincrónico, la dimensión diacrónica permitiendo la comparación no sólo de casos diferentes en un mismo momento, sino casos similares a lo largo de la historia, tanto en el mismo país como en países diferentes. De esta forma, se profundiza, frente a los estudios que priorizan la base cuantitativa, lo cualitativo como válido para el método comparativo (Llamazares, 1995). 
De todas formas, si podemos establecer que un punto central es concentrarse, por un lado en la aclaración de los conceptos, en establecer claramente de qué estamos hablando como elemento comparativo. Otro aspecto fundamental hace a las técnicas utilizadas para el desarrollo de la comparación y en qué medida las dimensiones de espacio y tiempo en su relación similitud o diferencia pueden ser un obstáculo o simplemente elementos diferenciadores desde el contexto.

\section{Conclusión}

Aún queda mucho por investigar entre las propuestas metodológicas, tanto desde las Ciencias Políticas como desde la Historia, por ello, nos reconocemos en proceso de reflexión y análisis, por tanto, este no es un texto acabado sino notas y apuntes introductorios para compartir y debatir con otros colegas un aspecto que nos resulta relevante y de un enorme potencial.

Así, entendemos necesario seguir conociendo los distintos casos, para poder seguir conceptualizando, y entonces, encontrar explicaciones que aporten al análisis de la totalidad, fundado de un modo exhaustivo, y atendiendo en la diacronía a las articulaciones específicas que las distintas formas de violencias han impuesto o continúan imponiendo. Debemos considerar, desde los efectos de la caída de la segunda República en España, a las consecuencias que supuso en América Latina la Doctrina de Seguridad Nacional hasta, las derivaciones que, en la última década, ha supuesto la difusión del narcotráfico, el crimen organizado, la corrupción. Pero también, el ejercicio de nuevas formas de represión ya ensayadas en Haití después del temblor de 2010 y hasta, por qué no, el surgimiento de sectores resistentes que reclaman incluso la autodeterminación, con más intensidad en la Araucanía Chilena o la Patagonia Argentina, frente al avance de empresas transnacionales o de los propios estados en torno a la cuestión ambiental. La larga duración nos permite inscribir procesos que a priori parecieran escindibles.

Analizar narraciones y discursos, estereotipos y caracterizaciones nos permite deslindar los alcances de la legitimidad propuesta "desde arriba" enriqueciendo las posibilidades de interpretación al resignificar la acción "desde abajo". Recrear y problematizar el contexto ideológico del fenómeno es específico para desarrollar estrategias tendientes a la formulación de indicadores adecuados.

Los exilios en particular, pero las movilidades forzadas en general, son experiencias profundamente traumáticas, alteran la integridad del sujeto, que interrumpe violentamente su proyecto de vida, y su sentido de pertenencia e identidad social. Pero también, como bien señala Inés Rojkind, cuando retoma a León Rozitchner, el exilio es “... un refugio: la contraparte del encierro, de la amenaza de tortura y del terror a la muerte. (...) abría a los que habían huido la posibilidad de escapar del terror y, en definitiva, de seguir viviendo. Por eso subrayaba, "lo cierto es que todo exiliado es un ser gratificado, el que participa de una nueva posibilidad que le fue abierta como crédito inesperado; al haber eliminado la presencia mortal de la represión". El exiliado era, entonces, porque había tenido la oportunidad de sobrevivir, "un ser de excepción." (Yankelevich, 2004: 245) En algún punto, a partir de sus evocaciones, puede afirmarse que lograron derrotar a la dictadura porque consiguieron seguir vivos (Gatica, 2011: 374).

Para concluir, expresamos que explorar las posibilidades de lo comparativo nos llevaría a cumplir con un doble objetivo, por un lado, a la necesidad de conocer más las experiencias particulares, tanto desde lo 
nacional como desde lo experiencial, como base para generar elementos comparables. Y, en segundo lugar, encontrar esas similitudes y diferencias que nos permitirían clarificar conceptos, conocer estrategias, actitudes, respuestas, que arrojaran luz sobre las respuestas humanas, sociales, políticas y hasta culturales frente a las movilidades forzadas.

Es dable atender que esta perspectiva de análisis encierra también la posibilidad de suscitar interrogantes que surgen y se hacen evidentes al momento de trabajar las tensiones entre la corta y la larga duración; entre distintos espacios nacionales o regionales -incluso locales-; pero también a partir de las comparaciones que las distintas claves interpretativas representan. Así la perspectiva de género que no homogeneiza en mujeres u hombres, sino que atiende a las distintas sexualidades; o la cuestión generacional para el exilio que comienza a ser abordada en profundidad a partir de los últimos años; incluso la trascendencia y el compromiso que subyacen en los análisis de colectivos afrodescendientes, instalan una nueva agenda de problemas.

\section{Referencias}

Andujar, Andrea y otras. 2009. De minifaldas, militancias y revoluciones. Exploraciones sobre los 70 en Argentina. Buenos Aires: Ediciones Luxemburg.

Bloch, Marc. 1982. Introducción a la historia. Buenos Aires: FCE.

Bloch, Marc. 1999. Historia e historiadores. Madrid: Akal.

Chambers, Iain. 1995. Migración, cultura, identidad. Buenos Aires: Amorrortu Editores.

Chedid, Saad. 2003. El legado de Edward W Said. Buenos Aires: Ed. Canaán.

Coraza de los Santos, Enrique. 2001. El Uruguay del exilio: la memoria, el recuerdo y el olvido a través de la bibliografía, Scripta Nova. Revista electrónica de Geografía y Ciencias Sociales, 94.

Coraza de los Santos, Enrique. 2005. Viajes de ida y vuelta: exilios entre España y Uruguay en el siglo XX. En Actas X Jornadas Interescuelas/Departamentos de Historia. Rosario: Universidad Nacional de Rosario. Coraza de los Santos, Enrique. 2006. España de mil destierros. En El Uruguay del exilio: gente, circunstancias, escenarios. Coordinado por Silvia Dutrénit. Montevideo: Ed. Trilce, 215-256.

Coraza de los Santos, Enrique. 2014. Territorialidades de la migración forzada. Los espacios nacionales y trasnacionales como estrategia política. Espacialidades, 4 (1): 197-221.

Coraza de los Santos, Enrique. 2015. Migraciones forzadas en América Latina en perspectiva comparada. Projeto História, 53: 11-55.

Coraza de los Santos, Enrique y Silvia Dutrénit. 2010. De vidas migrantes y derroteros peregrinos. Exilios y redes entre el Cono Sur y España en el siglo XX. En. Winnipeg, el exilio circular, editado por Ana Lenci, Ingrid Jasckek, Isabel Piper, Ricard Vinyes. Santiago: Programa Domeyko Sociedad y Equidad, 35-42.

Coraza de los Santos, Enrique y Dinorah Aldana. 2014. Para la mayoría de ellos el tiempo se les paró. La problemática del retorno de las migraciones forzadas, un intento comparativo entre Uruguay y El Salvador. Ponencia presentada en XII Congreso de Historia de Centroamérica, San Salvador.

Dutrénit, Silvia. 2006. El Uruguay del exilio: gente, circunstancias, escenarios. Montevideo: Ed. Trilce. Dutrénit, Silvia, Eugenia Allier y Enrique Coraza de los Santos. 2008. Tiempos de exilios. Memoria e historia de españoles y uruguayos. Montevideo: Ed. Textual. 
Forster, Ricardo. 1999. El exilio de la palabra. Ensayo en torno a lo judío. Buenos Aires: Eudeba.

Galeana, Patricia. 2014. Historia comparada de las migraciones en las Américas. México: UNAM-IPGH. Gatica, Mónica. 2011. ¿Exilio, migración, destierro? Los trabajadores chilenos que se asentaron en el Noreste de Chubut a partir de Septiembre de 1973: Memorias, historias e implicancias. Tesis de doctorado, Buenos Aires: Universidad Nacional de La Plata.

Gatica, Mónica. 2014. El exilio chileno en el NE de Chubut. Problematizando un estudio de caso. Ponencia presentada en II Jornadas de trabajo sobre Exilios Políticos del Cono Sur en el siglo XX. Agendas, problemas y perspectivas conceptuales, Montevideo.

Groppo, Bruno. 2000. Los exilios europeos en el siglo XX. París, MIMEO.

Guelerman, Sergio. 2001. Memorias en presente. Identidad y transmisión en la Argentina posgenocidio. Buenos Aires: Grupo Editorial Norma.

Jensen, Silvina. 1998. La huida del Horror no fue olvido. El exilio político argentino en Cataluña 1973-1983. Barcelona: Editorial Bosch.

Jensen, Silvina. 2004. Suspendidos de la historia/Exiliados de la memoria. El caso de los argentinos desterrados en Cataluña (1976- ...). Tesis de doctorado, Barcelona.

Jensen, Silvina. 2010. España-Cono Sur: una interminable cadena de exilios y retornos. En Winnipeg, el exilio circular, editado por Ana Lenci, Ingrid Jasckek, Isabel Piper, Ricard Vinyes. Santiago: Programa Domeyko Sociedad y Equidad, 43-46.

Jensen, Silvina. 2014. Agendas para una historia comparada de los exilios masivos del siglo XX. Los casos de España y Argentina. Paracarina del Sur, 20.

Lastra, Soledad. 2014. Semillas de la recepción a los retornados del exilio argentino y uruguayo (19831985). Revista Cantareira, 20: 71-90.

Lida, Clara. 2002. Enfoques comparativos sobre los exilios en México: España y Argentina en el siglo XX. En México, país de refugio: la experiencia de los exilios en el siglo XX. Coordinado por Pablo Yankelevich. México: Plaza y Valdés, 205-217.

Llamazares, Iván. 1995. El análisis comparado de los fenómenos políticos. Una discusión de sus objetivos metodológicos, supuestos metateóricos y vinculaciones con los marcos teóricos presentes en las Ciencias Sociales Contemporáneas. Revista de Estudios Políticos, 89: 281-297.

Mellone, Vivian. 2014. Londres, capital del exilio mediterráneo. Un estudio comparado entre la comunidad española y la italiana (1823-1833). En Entre mediterráneo y atlántico. Circulaciones y miradas 17561867. Coordinador por Antonino De Francesco, Luigi Mascilli y Raffaele NocereE. Santiago de Chile: FCE, 437-456.

Pagni, Andrea. 2011. El exilio republicano español en México y Argentina. Historia cultural, instituciones literarias, medios. Madrid: Iberoamericana.

Pérez, Aníbal. 2007. El método comparativo: fundamentos y desarrollos recientes. Pittsburgh: Universidad de Pittsburgh.

Pla Brugat, Dolores. 2007. Pan, trabajo y hogar. El exilio republicano español en América Latina. México: Instituto Nacional de Migración, Centro de Estudios Migratorios, Instituto Nacional de Antropología e Historia, DGE Ediciones.

Pollak, Michael. 2006. Memoria, olvido, silencio. La producción social de identidades frente a situaciones límite. Buenos Aires: Ediciones al margen. 
Pozo, José del . 2006. Exiliados, emigrados y retornados chilenos en América y Europa, 1973-2004. Santiago: RIL Editores.

Ramos, Leonidas. 2012. Método comparado: precisiones y características. Revista de Ciencias Políticas, 16. Roniger, Luis y Mario Sznajder. 2005. El legado de las violaciones de los derechos humanos en el Cono Sur. Argentina, Chile y Uruguay. La Plata: Ediciones al Margen.

Sánchez, Nicolás. 2002. El exilio español en perspectiva comparada. En México, país de refugio: la experiencia de los exilios en el siglo XX. Coordinado por Pablo Yankelevich. México: Plaza y Valdés, 197-204 Sartori, Giovanni. 2011. Cómo hacer ciencias políticas. Madrid: Taurus.

Sartori, Giovanni y Leonardo Morlino. 1994. La comparación en las ciencias sociales. Madrid: Alianza. Sznajder, Mario y Luis Roniger. 2010. La política del destierro y el exilio en América Latina, México: FCE. Thompson, Paul. 2004. Historia oral y contemporaneidad. Historia, memoria y pasado reciente, 20: 14-34. Tilly, Charles. 1991. Grandes estructuras, procesos amplios, comparaciones enormes. Madrid: Alianza Editorial. Winton, Ailsa, Luis Arriola, Enrique Coraza de los Santos, Martha García Ortega y Germán Martínez. 2014. Control y crisis en las fronteras: retos contemporáneos de las migraciones en México. ECOfronteras. 52: pp. 14-17.

Yankelevich, Pablo y Silvina Jensen. 2007. Exilios. Destinos y experiencias bajo la dictadura militar. Buenos Aires: Libros del Zorzal. 